\title{
Contribution of Proteomics for Diving into the Lactic Acid Bacteria Role and the Modification of the Food Matrix during Fermentation
}

\section{Silvina Fadda*}

Scientific Researcher, Centro de Referencia para Lactobacilos (CERELA-CONICET), Tucuman, Argentina

Fermentation and drying can be considered as the oldest ways to preserve raw materials extending the shelf-life as well as enhancing the flavour and nutritional qualities of the products. Lactic acid bacteria (LAB) are the main agents responsible for fermentation, reducing the ripening time, minimizing manufacturing defects, improving sensory properties and inhibiting the development of pathogenic and spoilage flora. LAB is also considered as the most important microorganism responsible for the health-promoting effects of fermented foods, especially in milk-derived products. Indeed, strains of some species have traditionally been used as probiotics and added as functional bacteria in various food commodities [1]. Due to the huge economic significance of industrial application of LAB as starters, biopreservatives and probiotics, a research emphasis on their metabolism, genetic and applications has been placed in the last 25 years [2].

Before the development of genomics, scientists focused their investigations on single or small groups of genes or proteins. The genome-sequencing projects of the late 1990s yielded entire genome sequences of many bacteria and yeasts, leading to a huge amount of genetic data. The introduction of user-friendly and browser-based bioinformatics tools to extract information from these databases constitutes a key development of the post genomic era. It is now possible to search entire genome sequences for specific nucleic acid or protein sequences to have a global view of living organisms through in silico analyses. Transcriptomics, proteomics, metabolomics and integromics are the main new technologies arisen from genomics that aim at understanding biological systems by its analysis and characterization in unknown details (thousands of genes and proteins detected simultaneously). This represents a challenge for scientific analysis and opens new perspectives for bacterial starter research purposes.

The metabolic potential of LAB can be firstly hypothesized by means of genome sequence analysis and bioinformatics as illustrated by Siezen et al. [3]. As an example, the complete genome sequence of Lactobacillus sakei $23 \mathrm{~K}$, a psychrotrophic LAB species naturally present in fresh meat determined the existence of a specialized gene catalog related to its ability to survive and compete in meat environments [4]. Many genes seem to be responsible for overcoming the harsh conditions of meat processing, such as redox and oxygen level shifts. Also, genes related to biofilm formation that allow colonization of meat surface were revealed. By using proteomics, some of the above mentioned functions have been experimentally proven to be very important for $L$. sakei to meat adaptation [5-7], thereby confirming the predicting value of genome data mining. In this sense, the knowledge of the mechanisms involved in such adaptations is thus essential for selecting the most efficient strains for a particular product. Furthermore, food industry is interested in using stable starter cultures with good processing adaption capability. Variations in temperature, osmotic conditions, oxidative or acidic environments are situations to which $\mathrm{LAB}$ are routinely subjected. The proteomic approach constitutes auseful tool being applied in this times to study the molecular basis of bacterial adaption to harmful conditions. Previously, these proteomic approaches were rather descriptive being focused on protein identification. Currently, more complete studies combining proteomics, transcriptomic and metabolomics are bringing new clues for understanding LAB physiology under these stressful environments. van de Guchte et al. [8] made a clear revision using a proteomic approach on the molecular mechanisms of probiotic bacteria for withstanding GIT conditions.

Also, proteomic tools are used to study food matrix systems to achieve an efficient characterization of biochemical mechanisms undergoing during fermentation and ripening. In fact, the proteome of a food is a dynamic entity which reflects the environment and physiological state of the origin organisms and evolves in time. In fact, food proteins can particularly be subjected to further change during food storing and maturation. For instance, proteolytic phenomena heavily modify the picture of the protein content in foods such as cheese and fermented meat products. Thus, high throughput approaches such as proteomic have permitted the characterization of food components such as the study of their functional, nutritional and biological relevance protein conformation and protein interactions, as well as food quality assessment. Moreover, proteomic approaches have been applied to correlate proteolytic profiles with technological parameters in view to detect valuable biomarkers to monitor and predict meat quality $[9,10]$. Certain peptidic fractions originated from meat and meat fermented products have been identified to be related to sensory attributes [1113]. As a consequence of maturation processes, bioactive peptides can be produced in the food matrix by endogenous and/or bacterial enzyme activity; these bioactive peptides can be discovered either empirically or by prediction [14]. It launched the nutritional peptidomics as the discipline focused on the discovery and validation as well as the study of health effects of bioactive food peptides, making a complete revision of both the classical hydrolysis strategy and the bioinformatics-driven reversed genome engineering.

It is envisioned that the information gained by the combination of "Omics" approaches leads to a knowledge-based selection of LAB. This constitutes an invaluable tool for the improvement of established fermented foods or for the development of novel ones, based on the ability of selected starters to better compete/adapt and produce metabolites of technological or health interest obtaining functional cultures with improved capabilities. As a final point, the comprehension of the food matrix evolution during ripening by means of the post genomic technologies will contribute to improve

*Corresponding author: S. Fadda, Scientific Researcher, Centro de Referencia para Lactobacilos, San Miguel de Tucumán, T4000ILC, Argentina, Tel: +54 381 4310465, Fax: +54 381 4005600; E-mail: sfadda@cerela.org.ar

Received August 16, 2012; Accepted August 18, 2012; Published August 20 2012

Citation: Fadda S (2012) Contribution of Proteomics for Diving into the Lactic Acid Bacteria Role and the Modification of the Food Matrix during Fermentation. Single Cell Biol 1:e113. doi: 10.4172/2168-9431.1000e113

Copyright: (c) 2012 Fadda S. This is an open-access article distributed under the terms of the Creative Commons Attribution License, which permits unrestricted use, distribution, and reproduction in any medium, provided the original author and source are credited. 
Citation: Fadda S (2012) Contribution of Proteomics for Diving into the Lactic Acid Bacteria Role and the Modification of the Food Matrix during Fermentation. Single Cell Biol 1:e113. doi: 10.4172/2168-9431.1000e113

fermentation processes obtaining a modern food industry with lower processing/production costs and higher-quality end-products.

\section{Refrences}

1. Ljungh A, Wadstrom T (2006) Lactic acid bacteria as probiotics. Curr Issues Intest Microbiol 7: 73-89.

2. Gasson MJ, de Vos W (2004) Genetics and Biotechnology of Lactic Acid Bacteria, Springer-Verlag New York, LLC.

3. Siezen RJ, Van Enckevort FH, Kleerebezem M, Teusink B (2004) Genome data mining of lactic acid bacteria: the impact of bioinformatics. Curr Opin Biotechnol 15: 105-115.

4. Chaillou S, Champomier-Vergès MC, Cornet M, Crutz-Le Coq AM, Dudez AM, et al. (2005) The complete genome sequence of the meat-borne lactic acid bacterium Lactobacillus sakei 23K. Nat Biotechnol 23: 1527-1533.

5. Marceau A, Zagorec $M$, Chaillou $S$, Méra $T$, Champomier-Vergès MC, et al. (2004) Evidence for involvement of at least six proteins in adaptation of Lactobacillus sakei to cold temperatures and addition of $\mathrm{NaCl}$. Appl Environ Microbiol 70: 7260-7268.

6. Fadda S, Anglade P, Baraige F, Zagorec M, Talon R, et al. (2010). Adaptive response of Lactobacillus sakei $23 \mathrm{~K}$ during growth in the presence of meat extracts: A proteomic approach. Int J Food Microbiol 142: 36-43.

7. McLeod A, Zagorec M, Champomier-Vergès MC, Naterstad K, Axelsson L
(2010) Primary metabolism in Lactobacillus sakei food isolates by proteomic analysis. BMC Microbiol 10: 120.

8. van de Guchte M, Chaze T, Jan G, Mistou MY (2012) Properties of probiotic bacteria explored by proteomic approaches. Curr Opin Microbiol 15: 381-389.

9. Te Pas MF, Jansen J, Broekman KC, Reimert H, Heuven HC (2009) Postmortem proteome degradation profiles of longissimus muscle in Yorkshire and Duroc pigs and their relationship with pork quality traits. Meat Sci 83: 744-751.

10. Paredi G, Raboni S, Bendixen E, de Almeida AM, Mozzarelli A (2012) "Muscle to meat" molecular events and technological transformations: The proteomics insight. J Proteomics 75: 4275-4289.

11. Sentandreu MA, Stoeva S, Aristoy MC, Laib K, Voelter W, et al. (2003) Identification of small peptides generated in Spanish dry-cured ham. J Food Sci 68: 64-69.

12. Mora L, Sentandreu MA, Toldrá $F$ (2010) Identification of small troponin $T$ peptides generated in dry-cured ham. Food Chem 123: 691-697.

13. Fadda S, López C, Vignolo G (2010) Role of lactic acid bacteria during meat conditioning and fermentation: peptides generated as sensorial and hygienic biomarkers. Meat Sci 86: 66-79.

14. Panchaud A, Affolter M, Kussmann M (2012) Mass spectrometry for nutritional peptidomics: How to analyze food bioactives and their health effects. J Proteomics 75: 3546-3559. 